\title{
Caracterização das funções do coordenador técnico em basquetebol: estudo realizado com os clubes da associação de basquetebol de Aveiro
}

\author{
Nuno Leite \\ Victor Maçãs \\ Jaime Sampaio \\ Marina Carvalho
}

Departamento de Ciências do Desporto, Exercício e Saúde Universidade de Trás-os-Montes e Alto Douro Portugal

\section{RESUMO}

No Basquetebol actual, o coordenador técnico tem uma importância estratégica na planificação, ao estabelecer objectivos e decidindo como os concretizar, o que implica sistematização e antecipação do futuro em todo o processo. A sua actividade no planeamento estratégico, enquanto planeamento estruturante, é fulcral, na competitividade e desenvolvimento sustentável do clube, pois, permite definir a direcção das organizações em sentido mais lato e no longo prazo, estabelecendo objectivos abrangentes e posicionando a organização no ambiente em que opera. Assim, o objectivo principal deste estudo foi caracterizar a actividade desenvolvida pelos coordenadores técnicos nos clubes de Basquetebol pertencentes à Associação de Basquetebol de Aveiro, numa visão dinâmica e prospectiva da sua intervenção enquanto gestor profissional, ficando-se a conhecer o seu papel no processo de recrutamento e formação de treinadores e jogadores, e a forma de cooperação entre estes e o Director Técnico Regional. Para responder aos problemas e objectivos do estudo, concebemos um modelo de análise que incidiu sobre uma amostra de vinte e um clubes de Basquetebol, relativa a vinte e um coordenadores técnicos. A recolha dos dados foi realizada através da análise documental e de um questionário aplicado em entrevista $(n=21)$. O tratamento foi possível através do registo e codificação dos dados para o software SPSS e com base na análise estatística descritiva e de conteúdo. Os resultados desta investigação permitiram-nos constatar uma grande heterogeneidade nos clubes, podendo até existir mais do que um coordenador técnico, existindo até mesmo alguns casos, quem não apresente este elemento por apenas possuírem uma equipa. Os coordenadores técnicos são maioritariamente do sexo masculino e bastante jovens, possuindo simultaneamente um elevado grau de formação académico e específico em basquetebol. Apesar dos coordenadores técnicos estarem ligados à modalidade há muitos anos, só recentemente passaram a exercer essa função específica, onde encontramos um conjunto algo homogéneo de tarefas, variáveis de acordo com as crenças e filosofia dos clubes. Por último, o Director Técnico Regional estabelece com estes contactos informais, não existindo uma cooperação efectiva.

Palavras-chave: perfis profissionais, coordenador técnico, basquetebol

\begin{abstract}
Characterization of the roles of a basketball technical coordinator: study in the basketball association clubs of Aveiro

In Basketball, the technical coordinator has a strategic importance in planning, by establishing goals and deciding how to make them real, which involves systematization and anticipation of the future in the whole process. His activity works like a fulcrum, in the competitiveness and sustainable development of the club, allowing organizations to define the long term development philosophy, establishing several goals and positioning the organization in the environment in which it operates. So, the main goal of this study was to characterize the activity developed by the technical coordinators in the clubs of Aveiro Basketball Association, in a dynamic and prospective vision of his intervention while professional manager. The data gathering was carried out through the documentary analysis and a questionnaire applied in interview $(n=21)$. In order to accomplish the register and codification of the data (statistical descriptive analysis and of content) we used software SPSS.

The result of this investigation allowed us to note a great heterogeneity in the clubs, being able up to exist more than a technical coordinator, there are even some cases, which do not present this element because they only have a team. The technical coordinators are mainly males and young, having simultaneously a high and specific degree in basketball. About they're connection to basketball, only recently they started to practise this specific function, where we find a homogeneous set of tasks, which may vary according to the beliefs and philosophy of the clubs.
\end{abstract}

Key-words: professional profile, technical coordinator, basketball 


\section{INTRODUÇÃOO}

O Basquetebol é actualmente uma modalidade praticada em todo o mundo e a que as associações dão uma especial atenção, promovendo-o e gerindo-o recorrendo a técnicos cada vez mais especializados. O papel do coordenador técnico tem sido objecto de uma insuficiente reflexão, o que em nosso entender comporta alguns factores negativos, já que este é essencial no plano do desenvolvimento do Desporto. Nas organizações de Basquetebol profissional e não profissional em Portugal, os coordenadores técnicos enquanto gestores desportivos têm necessidade de formação e requalificação especializada.

Não podemos ignorar o quadro, por vezes difícil e complexo, em que muitos coordenadores técnicos exercem na grande maioria dos casos benevolamente, a sua acção. Por estas razões, a realização deste trabalho, surge como contributo ao entendimento da função do coordenador técnico, e decorrente desta, a necessidade da respectiva formação.

\section{Objectivos}

O modelo de análise teve por base os seguintes objectivos: i) caracterizar os recursos humanos/coordenador(es) técnico(s) nos clubes da Associação de Basquetebol do distrito de Aveiro (ABA); ii) descrever e comparar os dados biográficos, nomeadamente os referentes à formação e experiência profissional dos coordenadores técnicos nos clubes da ABA; iii) descrever e comparar a natureza e duração das actividades de gestão desenvolvidas pelos coordenadores técnicos em cargos de direcção e de treino, nos clubes da ABA; iv) caracterizar as funções desenvolvidas pelos coordenadores técnicos nos clubes da ABA; e, por último, v) conhecer de que forma o Director Técnico Regional (DTR) coopera com os coordenadores técnicos dos clubes da ABA.

\section{MATERIAL E MÉTODOS \\ Participantes}

A população deste estudo é constituída por todos os coordenadores técnicos das vinte e uma [21] secções de Basquetebol dos clubes pertencentes à Associação de Basquetebol de Aveiro.

\section{Instrumentos}

O instrumento utilizado para o estudo foi um questionário, necessário para analisar a existência de coordenadores técnicos de Basquetebol nos clubes, conhecer os seus dados biográficos, nomeadamente nível de formação e experiência profissional, a natureza e duração das actividades desenvolvidas por estes, as funções da sua responsabilidade dentro da secção de Basquetebol, e ainda, conhecer de que forma os DTR cooperam com os clubes.

O questionário apresenta-se dividido em seis partes distintas: (i) identificação do coordenador técnico; (ii) nível de formação e experiência profissional; (iii) funções; (iv) processo de recrutamento e formação de treinadores; (v) processo de captação, selecção e formação de jogadores; (vi) interacção com o exterior.

\section{Procedimentos}

Ao longo do estudo os procedimentos metodológicos foram desenvolvidos em várias etapas, aqui descritas de uma forma genérica:

Etapa I - O conhecimento empírico e a análise documental permitiu-nos concluir que das 21 associações de Basquetebol existentes a nível nacional, a ABA apresenta um peso relevante na panorâmica do Basquetebol nacional, contendo, uma grande maioria dos clubes, equipas nas competições nacionais, a nível masculino e feminino. Pelo que, pensámos centrar o nosso estudo nas funções do coordenador técnico, inquirindo desta forma todos os clubes desta associação.

Etapa II - A partir da revisão da literatura, procedemos à construção do questionário, que foi analisado, reformulado e validado por especialistas, para posteriormente se proceder à sua aplicação para recolha de dados.

Etapa III - Efectuado um levantamento dos clubes inscritos na $A B A$ na presente época desportiva 2006/2007, no decurso do mês de Maio de 2007 procedeu-se à recolha de dados através do questionário. $\mathrm{Na}$ presença do inquiridor os coordenadores técnicos responderam ao questionário e sempre que surgia alguma dúvida, esta era devidamente esclarecida.

\section{Tratamento estatístico}

Etapa IV - Depois de recolhida a informação procedeuse ao seu registo e codificação, sendo todos os cálculos estatísticos necessários realizados no SPSS 14.0. De uma forma genérica, foi utilizada a análise estatística descritiva, através da distribuição de frequências e 
percentagens. A partir daí recorreu-se a representações gráficas que traduzem a distribuição dos valores das variáveis. A pesquisa documental completou os dados obtidos através dos questionários.

\section{RESULTADOS E DISCUSSÃO}

A discussão dos resultados foi orientada de acordo com os cinco objectivos formulados e feita tendo por base a apresentação detalhada e exaustiva dos resultados do estudo, procedendo à discussão dos elementos mais significativos, apresentando algumas reflexões pessoais alicerçadas na opinião de diferentes autores.

1) Os 21 clubes inquiridos representam $100 \%$ da população estudada e apenas dois $(8,7 \%)$ não apresentam coordenador técnico referindo como motivo, o apresentarem apenas uma equipa na secção, não considerando necessária a função do coordenador técnico. Dos clubes que possuem este elemento, é importante referir, que alguns apresentam mais do que um, cabendo a cada um deles a responsabilidade de um grupo de equipas ou escalões, de acordo com os objectivos globais traçados no plano estratégico do clube. Nos clubes da ABA existem assimetrias consideráveis quanto à existência de coordenadores técnicos, o que não se pode explicar, apenas pela natureza desportiva, na medida em que esta está dependente da inter-relação de factores sociais, culturais, económicos e políticos traçados pelos clubes, geralmente a longo prazo, pois alguns são muito menos ambiciosos, o que logo à partida condiciona os resultados que possam vir a alcançar. O papel do coordenador técnico como motor dinamizador das políticas a implementar, começa actualmente a ser reconhecido pelas associações como fulcral para atingir metas e objectivos traçados.

2) Verificou-se que $90,5 \%$ dos coordenadores técnicos são do género masculino, situando-se a maioria na faixa etária compreendida entre os 21-30 e os 3140 anos de idade, existindo apenas um coordenador com mais de 50 anos. Estes resultados eram previsíveis pois a "gestão estratégica" nos clubes desportivos é uma prática recente, e a coordenação técnica passou simultaneamente a ser considerada importante pelos clubes, sendo actualmente uma função com exigência técnica e que exige uma formação académica e específica considerável. Os coordenadores técni- cos mais jovens têm na generalidade um grau de formação mais elevado, o que não é díspar do que se verifica a nível da população portuguesa, sendo-o no entanto em relação à maioria dos técnicos e directores desportivos que têm um grau de formação relativamente baixo. Dos inquiridos $66,6 \%$ têm curso superior e $19 \%$ destes possuem cursos de pós-graduação. Verifica-se ainda que estes cursos são em $92,86 \%$ dos casos em áreas ligadas ao desporto e apenas um na área de gestão, o que é demonstrativo da exigência técnica desta função, sendo ainda evidenciado, pelo facto, de os inquiridos possuírem em 95,2\% dos casos um nível de formação em Basquetebol, sendo a maioria $(55,0 \%)$ de nível III. 3) A maioria dos coordenadores técnicos estão ligados à modalidade de Basquetebol há mais de 11 anos, tendo $90,5 \%$ dos mesmos sido praticantes. Podemos no entanto constatar que destes, a maioria só exerce a função de coordenador técnico há menos de 3 anos, possivelmente por ser um papel a que só na actualidade se começou a dar a relevância que esta tarefa tem realmente, na gestão global e na planificação estratégica dos clubes.

4) A generalidade dos coordenadores técnicos fazem trabalho de coordenação entre diversos escalões, com responsabilidade na coordenação de aproximadamente 6 equipas, sendo importante mencionar que $71,43 \%$ destes referem ser autónomos em relação à sua actuação enquanto coordenadores técnicos, os restantes $28,57 \%$ dizem ser coadjuvados nessa função pelos dirigentes do clube. Na vida colectiva das secções, o sucesso e a eficácia exigem que quem dirige tenha capacidade de liderança e que seja autónomo nas suas decisões, devendo também ter colaboradores autónomos e responsáveis, capazes de se auto- disciplinarem, motivarem e prepararem. De acordo com Brito(2) para o caso concreto do Clube Desportivo da Póvoa e com Moutinho( ${ }^{(8)}$ para o Anadia Futebol Clube, os dados recolhidos vieram demonstrar que são da responsabilidade da generalidade dos coordenadores técnicos de Aveiro as seguintes funções, expostas ordenadamente pelo grau de importância atribuído: a) definir os objectivos gerais e as metas a atingir em cada escalão; b) definir os conteúdos técnicos a serem abordados em cada escalão; c) coordenar, supervisionar e avaliar o trabalho desenvolvido na formação; d) especificar e 
coordenar actividades da formação; e) definir metas desportivas a alcançar; f) definir o modelo de jogo para as equipas de formação; g) definir um perfil de treinador para cada escalão; h) definir a política desportiva da secção de Basquetebol; i) analisar e gerir os recursos humanos da secção; j) analisar e gerir os recursos materiais da secção; k) definir o modelo de treino para as equipas de formação. Para além destas funções, também é da responsabilidade de $93,8 \%$ dos coordenadores técnicos a elaboração do documento orientador do trabalho a realizar na secção. É importante que para além da planificação estratégica a longo prazo, existam planos a curto prazo e documentos orientadores específicos do trabalho a realizar pelas diferentes equipas e escalões do clube, que permitam cumprir os objectivos globais traçados. Esta relação, está de acordo com a definição de planeamento estratégico proposta por Sampedro(11), quando refere que o planeamento estratégico é um planeamento estruturante, que define a direcção das organizações em sentido mais lato, e no longo prazo estabelece objectivos abrangentes e posiciona a organização no ambiente em que opera.

Em 85,7\% das secções de Basquetebol dos clubes da ABA, é da responsabilidade dos coordenadores técnicos a preparação e organização das reuniões, geralmente mensais, de coordenação técnica, em que se encontram presentes todos os treinadores, e por vezes, elementos da direcção, o que nos leva a concluir que existe uma preocupação em acompanhar as equipas da secção e transmitir-lhes o caminho a seguir, de acordo com os objectivos gerais e específicos traçados. A maioria dos coordenadores técnicos (81\%), são ainda responsáveis pelo processo de recrutamento e formação dos treinadores nas suas escolas de Basquetebol, devido à importância estratégica atribuída pelo clube ao desenvolvimento do património humano, para assim, conseguir obter um grupo de treinadores e técnicos emersos na ideologia desportiva do clube, que sintam realmente as cores e que saibam que podem contar com a confiança dos dirigentes do clube. Desta forma, o clube terá dado um grande passo para criar uma estrutura técnica sólida. Neste processo de recrutamento de treinadores, o parâmetro considerado mais relevante pelos coordenadores técnicos é o nível de formação do treinador, o que era de esperar, pois estamos num universo de técnicos, com elevado nível de formação na modalidade, e que muitas vezes, são simultaneamente eles os próprios treinadores de alguns escalões. Para além, do nível de formação, são também parâmetros considerados importantes no recrutamento de treinadores, os seguintes: a) experiência em escalões de formação; b) perfil e filosofia do treinador; c) anos de experiência; d) perfil técnico.

É ainda preocupação dos coordenadores técnicos a formação contínua dos seus treinadores, contribuindo através, da divulgação da existência de acções e cursos de formação, havendo mesmo $50 \%$ das secções que organizam essas acções e $25 \%$ que as financiam, o que é demonstrativo do interesse em existirem técnicos permanentemente actualizados e eficientes. Segundo Araújo(1) a actividade "coaching" de qualquer coordenador técnico pressupõe informação e formação contínua, ensinar o esperado e gerir o inesperado, contidos no funcionamento de qualquer equipa de trabalho, tendo de ser realizado por quem seja capaz de, mais do que invocar o seu estatuto de autoridade, provocar nos componentes da equipa que lidera o reconhecimento dessa autoridade, de forma a que se consigam criar ambientes de trabalho onde, a competência seja reconhecida e incentivada.

Em 73,7\% das secções de Basquetebol dos clubes da $\mathrm{ABA}$, cabe ao coordenador técnico o processo de captação e formação de jogadores, desempenhando esta função individual ou conjuntamente com os treinadores e os dirigentes. De acordo com Ferreira ${ }^{(6)}$, também os clubes do distrito de Aveiro têm vindo a investir fortemente na formação, embora algumas decisões só no longo prazo apresentam resultados positivos, o que pode ser exemplificado com o que nos diz Comas ${ }^{(4)}$, que apresenta como uma das soluções para obter bons resultados a longo prazo, assumida actualmente por alguns clubes que se centram no desenvolvimento de programas de formação de jogadores na forma de escolas desportivas, conseguindo promover dentro dos clubes jogadores de qualidade, o que implica uma menor necessidade de fixar jogadores externos ao clube, conseguindo desta forma uma poupança em dinheiro e esforços. Também, desta forma, nos clubes da ABA têm vindo a dedicar-se à Preparação Desportiva a Longo Prazo, procurando desenvolver bases que permitam aos 
jogadores alcançar os objectivos finais ${ }^{(6)}$. A incorpo-

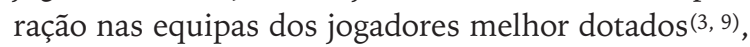
deve seguir um processo desenvolvido em três grandes fases: (i) detecção; (ii) selecção; e (iii) desenvolvimento dos talentos.

A segunda fase do processo acima descrito - selecção de jogadores, na opinião dos coordenadores técnicos dos clubes da ABA, apenas deve existir a partir do escalão de juniores ou até mesmo só no escalão de seniores. Desta forma, a maioria referiu que quando tinha muitos jogadores num dado escalão, construía equipa(s) "A" e "B", de forma a que todos os jogadores do clube competissem. Neste caso, consideram que a idade é o factor preponderante na decisão da ida de um jogador para a equipa "A" ou "B" de um determinado escalão. Os que coordenam para além de outros escalões, o escalão de juniores e/ou seniores, os aspectos fundamentais na selecção de jogadores são, ordenadamente pelo grau de importância, os seguintes: 1) Constituição física do jogador; 2 ) Fundamentos individuais ofensivos; 3) Fundamentos individuais defensivos; 4) Fundamentos tácticos ofensivos; 5) Fundamentos tácticos defensivos; 6) Anos de experiência como jogador; 7) Resultados obtidos noutros clubes; 8) Perfil do jogador; 9) Capacidades volitivas; 10) Idade.

As funções de coordenação técnica nas secções dos clubes, não são exercidas por profissionais em exclusividade, como seria desejável, mas sim cumulativamente com outras actividades profissionais, já que $57,2 \%$ são professores e $14,3 \%$ são técnicos ou gestores desportivos. A quase totalidade dos coordenadores técnicos ainda exerce no clube pelo menos mais uma actividade para além da coordenação técnica, sendo que, a maioria são simultaneamente treinadores de pelo menos um escalão. Cada vez mais se constata que a coordenação técnica deve ser um papel desenvolvido em exclusividade e assumido como profissão, para evitar uma sobrecarga psicológica e física que actualmente é imposta aos técnicos que têm de exercer além da sua profissão todo um conjunto de funções dentro do clube, muitas vezes com carácter de voluntariado, o que não é compatível com o profissionalismo que a função de coordenador técnico exige.

5) Ao nível da coordenação da secção os coordenadores técnicos estabelecem diversos contactos com o exterior, um destes é estabelecido em $81 \%$ dos casos com a ABA, particularmente, com o DTR $(66,7 \%)$. Estes contactos são geralmente informais, e as poucas reuniões efectuadas são geralmente esporádicas, existindo ainda, algumas reuniões periódicas e alguns ofícios circulares que são enviados pelo DTR. Esta situação é preocupante face ao estatuto e às funções que este apresenta, ou deveria apresentar a nível do desenvolvimento do Basquetebol da região de Aveiro, pois o DTR é um técnico a quem se reconhece autoridade no domínio técnico-pedagógico da modalidade, cujas referências se associam à competência, conhecimento e prestígio na área, que deveria coordenar as actividades e solucionar problemas de fundo da modalidade, particularmente aqueles que se relacionam com o desenvolvimento desportivo, e ainda, apoiar as iniciativas que se inserem nos planos de desenvolvimento da modalidade $(5,7,10)$. No longo prazo a cooperação entre estas entidades e os clubes, particularmente com o coordenador técnico, deve ser mais efectiva para que a modalidade se desenvolva a nível nacional.

\section{CONCLUSÕES}

Nos clubes há heterogeneidade em termos da existência de coordenadores técnicos, de acordo com os objectivos globais traçados no plano estratégico, se na maioria existe um que coordena todos os escalões, há outros que apresentam mais do que um coordenador técnico, sendo cada um deles responsável por um grupo de equipas ou escalões, e alguns clubes não apresentam este elemento por apenas possuírem uma equipa.

Os coordenadores técnicos são maioritariamente do género masculino e situam-se na faixa etária dos 21 aos 40 anos de idade, possuindo um elevado grau de formação académico em áreas ligadas ao desporto e quase todos apresentam um nível de formação em Basquetebol, maioritariamente nível III.

A maioria dos coordenadores técnicos estão ligados à modalidade de Basquetebol há mais de 11 anos, tendo sido praticantes da modalidade, mas só exercem a função de coordenador técnico há menos de 3 anos.

De acordo com as crenças e filosofia dos clubes, são da responsabilidade da generalidade dos coordenadores técnicos de Aveiro um conjunto alargado de 
funções das quais se destacam a definição dos objectivos gerais e as metas a atingir em cada escalão, a definição dos conteúdos técnicos a serem abordados em cada escalão ou a coordenação, supervisão e avaliação do trabalho desenvolvido na formação. Face ao rol de funções apresentadas, constata-se que a coordenação técnica deveria ser exercida de uma forma profissional e em exclusividade, para que os clubes possam vir a atingir as metas a que se propõem. Finalmente, ao nível da coordenação externa das secções de Basquetebol dos clubes, a maioria dos coordenadores técnicos apenas estabelece contactos informais com o DTR e as poucas reuniões realizadas entre estes são geralmente esporádicas, não existindo cooperação efectiva.

\section{REFERÊNCIAS BIBLIOGRÁFICAS}

1. Araújo J (2001). Dirigir equipas, melhorar competências. $2^{\mathrm{a}}$ publicação. Porto: Team Work.

2. Brito N (2002). O percurso desportivo no atletismo. Porto: Universidade do Porto, Faculdade de Ciências do Desporto e de Educação Física.

3. Coloma M (2005). "Gestión de clubes de alto nível Planificación estratégica". Artigo apresentado no $3^{\circ}$ Congreso Ibérico de Baloncesto - Propuestas para un baloncesto de calidad, 1-3 Dezembro, Vitoria-Gasteiz, 9-14.

4. Comas M (1991). Baloncesto, Mas que un juego - Staff Técnico, sus funciones. Madrid: Gymnos Editorial.

5. Federação Portuguesa de Basquetebol (2004). Estatuto do Director Técnico Regional. Lisboa: s.n..

6. Ferreira A (2000). "Da iniciação ao alto nível: um percurso para (re)pensar". Revista Treino Desportivo, 9, Janeiro, $3^{\text {a }}$ série.

7. Junoy J (2005). "A vueltas com la deteccion de talentos en el baloncesto". Artigo apresentado no $3^{\circ}$ Congreso Ibérico de Baloncesto - Propuestas para un baloncesto de calidad, 1-3 Dezembro, Vitoria-Gasteiz, 71-81.

8. Moutinho J (2006). Projecto Desportivo da Época 2006/2007 do Anadia Futebol Clube (documento de circulação interna). Anadia: Anadia Futebol Clube. Não publicado.

9. Pinto D (1987). "A organização da seç̧ão de Basquetebol no clube". Revista O Treinador, 18, 4-7.

10. Pinto D, Sampedro J (2005). "O planeamento estratégico uma perspectiva transversal a dirigentes e treinadores". Artigo apresentado no $3^{\circ}$ Congreso Ibérico de Baloncesto Propuestas para un baloncesto de calidad, 1-3 Dezembro, Vitoria-Gasteiz, 131-140.

11. Sampedro J (1999). Análisis de la estrategia de los deportes. S.1.: Gymnos.

\section{CORRESPONDÊNCIA}

\section{Nuno Leite}

Universidade de Trás-os-Montes e Alto Douro

Departamento de Desporto

Quinta de Prados

Apartado 1013

5000-911 Vila Real

E-mail: nleite@utad.pt 